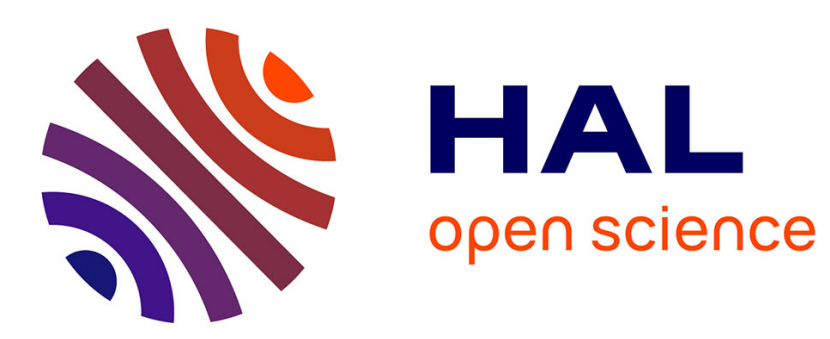

\title{
History and Intentions in the Experience of Artworks
}

Alessandro Pignocchi

\section{To cite this version:}

Alessandro Pignocchi. History and Intentions in the Experience of Artworks. Topoi, 2012, pp.1-10. 10.1007/s11245-012-9145-8. ijn_00750952

\section{HAL Id: ijn_00750952 \\ https://hal.science/ijn_00750952}

Submitted on 12 Nov 2012

HAL is a multi-disciplinary open access archive for the deposit and dissemination of scientific research documents, whether they are published or not. The documents may come from teaching and research institutions in France or abroad, or from public or private research centers.
L'archive ouverte pluridisciplinaire HAL, est destinée au dépôt et à la diffusion de documents scientifiques de niveau recherche, publiés ou non, émanant des établissements d'enseignement et de recherche français ou étrangers, des laboratoires publics ou privés. 


\title{
History and Intentions in the Experience of Artworks
}

Topoi DOI 10.1007/s11245-012-9145-8

\author{
Alessandro Pignocchi \\ Institut Jean Nicod, CNRS ENS-DEC EHESS, \\ Pavillon Jardin, 29 rue d'Ulm, 75005 Paris, France \\ pignocchi@hotmail.fr
}

\section{Abstract}

The role of personal background knowledge — in particular knowledge about the context of production of an artwork - has been only marginally taken into account in cognitive approaches to art. Addressing this issue is crucial to enhancing these approaches' explanatory power and framing their collaboration with the humanities (Bullot and Reber, in press). This paper sketches a model of the experience of artworks based on the mechanisms of intention attribution, and shows how this model makes it possible to address the issue of personal background knowledge empirically. I claim that the role of intention attribution in art experience has been incorrectly accounted in the literature because of an overly narrow definition of "intention." I suggest that the observer can recover not only the artist's abstract projects, but any kind of mental states that have played a causal role during the production of the work. In addition, I suggest that this recovery occurs in large part unconsciously and/or implicitly. I provide support for these claims by distinguishing three families of psychological mechanisms of intention attribution that are activated by artworks: one involved in the cognition of artifacts, one devoted to communication, and one involved in action perception.

\section{Cognitive approaches and history}

Until now, cognitive approaches to art have mainly searched for "artistic universals"that is, for properties of artworks that mark them as having an intrinsic artistic value (positive or negative) independent of the work's context of production. For instance, Ramachandran and Hirstein (1999) claimed that the elicitation of a peak-shift effect is an artistic universal. A peak-shift effect happens when a feature used by recognition processes is exaggerated and produces an unusually strong response in the underlying neural circuits. Ramachandran and Hirstein give the example of some Hindu statuettes that allegedly hyperactivate mechanisms for recognizing the female body by exaggerating the features that recognition processes use to 
distinguish female bodies from male bodies. Ramachandran and Histrein argued that the elicitation of a peak-shift effect is an artistic universal and that it confers atemporal artistic value.

John Hyman (2010) argued against the existence of artistic universals and showed that a peak-shift effect is judged as kitsch at least as frequently as it is judged to be artistically valuable. More generally, researchers in the humanities doubt the existence of artistic universals, arguing that the way we evaluate an artwork always depends on what we know about its context of production (Danto, 1981). For instance, we will not attribute the same value to an impressionist painting if we believe that it was painted in 1872 or last year (Genette, 1997). It seems plausible that we do not even see it in the same way (this point will be discussed in the last section of this paper). Other observations of the same kind indicate that a decontextualized account of artistic value would be at best extremely incomplete. The very same property can be evaluated (and probably seen) differently depending on its role in a given work and depending on the observer's background knowledge. For instance, an apparent brushstroke is evaluated differently in a photorealistic painting and in an impressionist painting. Moreover, the same apparent brushstroke in the same impressionist painting could both have been used as an argument to evaluate the painting negatively when it was painted and be used as an argument in favor of its excellence today.

For these reasons, Bullot and Reber (in press) argue that the main challenge for cognitive approaches to art is to show that they can take into account the role of historical background knowledge in the personal experience of an artwork. Addressing this point would also make it possible for those taking cognitive approaches to collaborate with researchers in the humanities, where the contextualization of an artwork is a major issue.

In this paper I sketch a cognitive approach to art based on the mechanisms of intention attributions. I show that an "intentional model" of the reception of artworks is ideally suited to investigate the role of personal historical background knowledge, since the intentions that we attribute to an artist when looking at her work depend on what we know about its context of production. If we believe that an impressionistic painting was painted at the beginning of the impressionist movement, we may see behind the brushstrokes, for instance, the intention of exploring a new kind of pictorial representation in the hope of capturing fleeting visual sensations. But if we believe instead that the painting is recent, we may see behind the strokes the intention of copying an old-fashioned style to please the eye of a naïve potential customer.

The next section sketches an intentional model of the reception of artworks. Then I provide arguments for the model based on existing work in the domains of artifact cognition, 
communication, and perception of action. In the final section I discuss how this intentional model can generate testable predictions and suggest a crucial question concerning how attributed intentions determine the perception of an artwork.

\section{The intentional model}

Although some authors have denied any role for intention attribution in the experience of artworks (Wismatt \& Beardsley, 1954), nowadays the majority recognizes that intention attribution must play some role (Danto, 1981; Iseminger, 1992; Levinson, 1979; Walton, 1970). However, this role may have been incorrectly described, or, at the least, some of its important components may have been neglected (Pignocchi, 2012). This is due, first, to an identification of the artist's intention with her conscious and abstract aims, as if a work of art could be produced on the basis of a single intention or a small set of them.

Levinson (1979) suggested a definition of art based on the intention of the artist. He proposed that $\mathrm{X}$ counts as art if it has been intended for regard in a way that preexisting artworks are or were regarded. The definition has been criticized for being too inclusive. Carroll (1999), for example, noted that nowadays many family photos are taken with the intention to produce a mimetic representation of their models and that they do not count as art despite the similarity with the kind of intentions that Renaissance painters had when producing art. Levinson (1989) answered this kind of criticism with the claim that "producing a mimetic representation" was not the only intention of the Renaissance painters. They generally also wanted their work to bear formal and expressive qualities, to display a certain amount of skill, to have various symbolic meanings, etc. In other words, Levinson argued that his detractors have a too-narrow conception of intentions (Pignocchi, in press). However, the intentions that Levinson mentioned still constitute an extremely small and partial subset of a painter's intentions. On their own, these kinds of quite abstract intentions would never lead to the production of a painting. The production of a painting requires many other kinds of mental states, including less abstract conscious aims, intuitions, emotions, non-propositional causal factors such as intentions in action and personality traits, and so forth.

The same narrow account of intention is found in debates about interpretation and meaning (Iseminger, 1992; see however Baxandall 1985; Wollheim, 1987, and, following Wollheim, Carroll, 2011). The authors generally seem to tacitly accept that the relevant intentions of the artist consist only of a few conscious and abstract aims. In this paper I will argue that local, unconscious and non-propositional intentions are at least as relevant to 
understanding our relations with artworks as the kind of general, propositional and abstract intentions generally mentioned in the literature.

In everyday social interactions, when we observe others' behavior, interact or communicate with them, we attribute a variety of mental states to them (for instance we attribute emotions very spontaneously, we take into account people's personality traits when interpreting or predicting their behavior, and we are able to attribute unconscious psychological properties to a person, at least through explicit reasoning and theorizing). Since there is no reason to believe that art experience activates special kinds of mechanisms of mental states attribution, the default hypothesis for an intentional model of our relationship to artworks is that during the experience of art we attribute the same range of mental states as in everyday social interactions. Thus, as a working definition, we should endorse a very broad account of the "artist's intentions." It should include all the mental states-conscious or not, propositional or not - that have played a causal role during the production of the work.

This definition is idiosyncratic and much broader than both the common and the theoretical use of the term. It is quite close, however, of the use made in some isolated but influential works such as Baxadall's Pattern of intention and Wollheim's Painting as an art (for a detailed comparison of my use of the concept of intention and Baxadall's see Pignocchi, 2012). Discussing Painting as an art, Carroll (2011) claimed that Wollheim position should be called "mentalist" and not "intentionalist" since it considers many kinds of mental states, including unconscious one, that are not traditionally considered as intentions. However, I want to try to subsume all of these mental states under the common label "intention," to insist on the notion of causality. In fact, the mental states that we care about, as spectators, are only those which have had a causal influence, through the actions and the decisions of the artist, on the appearance of the artwork. We are extremely permissive when we detect intentions behind the properties of a work: many intentions that we attribute to the artist are invented or, at least, projected (Pignocchi, 2012). However, a mental state that we believe to have left absolutely no traces in the appearance of the work (even if the artist himself claims it has) plays no role in our perception and appreciation of it (Wollheim, 1987).

The second reason that has led to an underestimation of the role of intentions is that authors generally only take into account the conscious attribution of intention, paradigmatically the intentions that are reconstructed by the critic or the art historian. However, like the intentions themselves, the attribution of intentions needs not be explicit and conscious. Here again, a preliminary argument comes from everyday social interactions: in our everyday life we also attribute mental states to others implicitly and/or unconsciously. 
Thus, the default working hypothesis is to consider that the same kind of implicit and/or unconscious intention attribution can happen during the experience of an artwork.

Contrary to a common assumption (Frith \& Frith, 2008), the distinction between implicit and explicit mental state attribution should not be equated with the distinction between conscious and unconscious mental state attribution. The implicit/explicit distinction refers to the way something is represented, whereas the conscious/unconscious distinction refers to phenomenal experience. An implicit mental state attribution happens when someone's behavior (or the result of this behavior) is perceived or interpreted in a way that is coherent with this behavior's being the outcome of a particular intentional process, but without representation of the relevant mental states as such (Butterfill \& Apperly, submitted). In fact, a behavior (or the result of a behavior) can be perceived as the result of intentions, but it need not be (it can be perceived as a mere physical event). For it to be perceived as intentional, the intentions of the agent do not need to be explicitly represented. It is enough for the perceptual appearance of the behavior to be segmented and organized in a way that is coherent with causation by the relevant kind of intentions. This implicit mode of intention attribution can, but need not, feed explicit intention attribution. For instance, the lines of a drawing can be perceptually organized as the result of specific kinds of actions (i.e. as having a beginning and an end, a direction, a speed, a pressure, as being organized in a particular sequence: Pignocchi, 2010) but without the intentions that have produced these lines being represented as such. At least theoretically, an implicit intention attribution of this kind can happen either consciously or unconsciously. Explicit intention attribution happens when the mental state attributed to someone is represented as such. Explicit intention attribution can be conscious or unconscious as well. Some theories of communication claim that understanding any sentence requires the explicit attribution of complex intentions to the speaker (Sperber, 2000). However, most of the time, these complex intention attributions remain unconscious. Kovacs et al. (2010) showed that a passive agent's belief about the presence or the absence of an object influences the speed of detection at which the participants who can represent that agent's belief detect it. This shows that participants explicitly represent the belief of the agent even if they are unaware of it.

A preliminary formulation of the intentional model could be as follows: the perception of an artwork activates rich intention attributions, implicit and explicit, conscious and unconscious, where the intentions attributed are potentially any kind of mental states that could have played a causal role during the production of the work. 
In the philosophy of art, one of the main issues is whether the intentions of the artist are important to determine the "true meaning" of an artwork or its "correct interpretation." Here, I do not want to frame the problem in terms of meaning since I do not want to "reify" or "essentialize" the concept of meaning by implying that there is something such as the "true definition" of what the meaning of an artwork is (Shusterman, 1999). The intentional model is about the mechanisms that underlie the experience of an artwork, not about what constitutes the "true meaning" of an artwork. However, it is important to verify that the intentional model is immune to the two main arguments given by anti-intentionalist philosophers in favor of the claim that intention attribution plays no role in the correct interpretation of artworks. The two arguments are the following: (1) artists' public declarations about their intentions are frequently irrelevant to interpreting an artwork (Beardsley, 1958) and (2) if the intentionalists were right, there would be only one correct interpretation of an artwork - that which conforms to the artist's intention — which does not seem to be the case (Gadamer, 1975; Ricoeur, 1976).

These two arguments rest on the tacit assimilation of artists' intentions with their propositional and conscious goals. When endorsing a wider conception of intention-one that sees the intentions of the artist as a causal process involving unconscious and nonpropositional mental states - both arguments fail. The first fails because artists, like anyone else, have limited access to the mental states that play a causal role in their behavior. Moreover, since some of their mental states have a non-propositional format (emotions, intuitions, images and sensations recalled in episodic memory, etc.) they, like anyone else, face the limits of language when describing the process by which their works are produced. Moreover, compared with simpler behavior, the production of an artwork is generally shaped by many intuitions, emotions, images, and other mental states that are impossible to fully describe verbally - the impossibility of capturing such mental states in words being a possible motivation for the production of the artwork.

For these two reasons - unconscious mental states and non-propositional mental statesthe verbal explanations of artists can be only very rough and simplistic approximations of the mental states that have shaped the production of their work. As spectators, we spontaneously consider artists' verbal explanations as just a set of cues, among many others - the work itself, what we know about its context of production, the artist's biography, and so forth - that can be used to infer some of the mental states that played a causal role in the production of the work.

The second argument fails for the same reasons: given the variety and complexity of the intentions that are at play in the production of an artwork and, in particular, given the 
importance of non-propositional intentions, no verbal interpretation of a work can even approach an exhaustive description of its production process. Trying to describe all of the intentions that have shaped a work of art is like trying to describe a movie (each color, each sound, each motion): any description, even a very accurate one, leaves room for an infinite number of other equally accurate descriptions. This is why an intentionalist view of interpretation is compatible with the observation that an artwork generally gives rise to a rich plurality of interpretations.

The next section provides details and support for the intentional model by distinguishing three kinds of mechanisms of intention attribution activated by artworks.

3. Processes of intentions attribution during the reception of artworks

\subsection{Function}

Empirical work in artifact cognition shows that the intended function of an artifact is determinant for its categorization. When there is a conflict between intended function and present use, the participant tends to see the intended function as the "genuine function" of the artifact that determines its true identity (for review see Boyer and Barrett, 2004). ${ }^{1}$ Preissler and Bloom (2008) showed that when children have to decide what a drawing represents, they spontaneously use contextual knowledge about its process of production. For instance, when children are asked to identify a drawing that looks like something intermediate between a spoon and a fork, the factor that determines their answer is the time the draftsman spent looking at each of the two during the production of the drawing.

Simple artifacts such as chairs and knifes generally have a unique and quite simple function that is characteristic of their category: to be sat on, cutting, etc. In our daily interactions with them, reference to the intention of their creator generally remains implicit and unconscious. Moreover, there is no need for precise contextual knowledge about the processes of production of these artifacts to know what they were built for.

Artworks, however, can fulfill a variety of functions, none of which is more typical or standard than the others. Moreover, many artworks fulfill many functions at once (Davies, 1991; Kaufman, 2002; Stecker, 1990). As we shall see in the example below, even a single property of an artwork (a shape, a given color, a brushstroke) can fulfill various functions. Thus, the impact of contextual knowledge on the attribution of function evidenced in children by Preissler and Bloom (2008) might be much more pervasive in the case of artworks than in

\footnotetext{
${ }^{1}$ From here onward I use "function" as a synonym of "intended function," although there are other accounts of what a function is (Parsons \& Carlson, 2008).
} 
the case of simpler artifacts. Moreover, the attribution of intention that determines the attribution of function is likely to be frequently explicit and to be present even at the scale of a single property.

Take Chardin's painting A Woman Drinking Tea. Imagine that at first sight I attribute to the painter the intention of producing a "realistic" painting, in the trivial sense of the word, that is to elicit an illusion of reality using conventional methods. In this case, both the face of the woman and the teapot would appear as not fully adequate. The features of the face are not clearly visible and they seem to vanish in the background. The teapot seems to be about to fall. Looking at it makes the eye uncomfortable.

Acquiring contextual knowledge about the painting's production might change the way I look at the woman's face and the teapot. Baxandall (1985) showed that Chardin drew on the scientific and philosophical theories about perception of his time-notably Locke's and Newton's empiricist theories - to produce subtle perceptual effects. Chardin knew that when looking at a painting, the eye of the beholder is attracted by faces and areas of strong contrast. In order to keep his painting from eliciting a straightforward pathway for the eye, Chardin blurred the features of the woman's face to weaken its attractive power. He also created a diffuse area of strong contrast along her arm so that the eye hesitates between the face and the arm. Chardin knew that the colors of a painting can create illusions of distance. Notably, cold colors tend to retract and give an impression of remoteness, whereas hot colors tend to expand and create the illusion of closeness. Chardin used this knowledge to create a complex interaction between colors and perspective on the teapot. The perspective of the teapot is false: the teapot seems to be in front of the table and about to fall (maybe this is why the drawer is opened: to receive the falling teapot). But since the teapot is painted in a colder color than the table, it tends to move backward in comparison to it. The colors tend to put the teapot that the perspective tries to cause to fall back on the table. Moreover, since colors are perceived mostly in the focal area, their effect is strongest when we look directly at the teapot. When the eye leaves it, perspective takes over and the teapot tends to appear to fall. Its strange position attracts the eye and, when the eye arrives at it, the colors move it back onto the table. Like the blurred face and the contrasted arm, the teapot tends to destabilize the perception of the painting. Through these effects, Chardin might have wanted his painting to elicit a more active exploration than traditional paintings do, as if the beholder were in front of a real moving three-dimensional scene and not a flat, static painting. In other words, Chardin wanted not to mimic the appearance of the things represented by his painting, to 
produce a conventional "realistic painting," but to mimic the movement the eye would have had in front of those things.

Pursuing my reading of Baxandall's Patterns of Intention, I learn that the woman in the painting is Chardin's first wife a few weeks before her death. At the time of painting she was already ill and Chardin knew it. Learning this adds a functional layer to the properties of the painting. The face of the woman is blurred not only to destabilize perception but also because the woman was already disappearing. The perceptually destabilizing effects that put the eye in an uncomfortable position when looking at this painting are intended not only to mimic the movements of the eye across a real scene but also to elicit the kind of unpleasant feeling that Chardin must have had during this period when looking at his wife, even when she was performing the most routine activities.

Learning this information about Chardin's (possible) intentions changes the way I categorize the painting - no longer as a "realistic painting" - and the way I evaluate itprobably more positively. It also changes how I look at the blurred face and the teapot: I no longer perceive them as failing to fulfill their function. The precise impact of this knowledge on perception is an open question.

Artifact cognition mechanisms are the only ones mentioned in arguments for a role of intention attribution in art experience in the literature (Levinson, 2007; Bullot \& Reber, in press). However, other mechanisms of intention attribution are also likely to be activated by artworks. The next section discusses the hypothesis that the properties of artworks activate the mechanisms involved in everyday communicative interactions (verbal or non-verbal).

\subsection{Communication}

Theories of human communication show that intention attribution is pervasive during the understanding of communicative acts, both verbal and non-verbal (Sperber \& Wilson, 1986). According to relevance theory, sentences are cues that speakers provide to allow hearers, using the context of enunciation and background knowledge, to retrieve what the speaker wants them to understand - the speaker's meaning. The psychological processes of intention reconstruction specialized in communication are activated by the detection of a communicative intention (Sperber \& Wilson, 1986; 2002). Ostensively addressing someone, for instance, is recognized as the expression of a communicative intention. But there are many other ways to express a communicative intention. Csibra (2010) argued that young infants recognize communicative intentions using cues such as eye contact, the intonation of the voice, and contingent reactivity to the infant's behavior. The work of Csibra and his 
collaborators shows that the detection of a communicative intention determines how children interpret and memorize a given behavior. If they detect no communicative intention, children try to understand the internal rationality of the behavior. When a communicative intention is detected, they look at the very same behavior as communicative and try to understand what the agent wants them to understand (Topal et al., 2008; Király et al., 2004).

In adults, there are many ways to make a communicative intention manifest. As with children, whether or not they detect a communicative intention influences the way they interpret a given behavior. If I am seated in front of you during dinner and I kick your leg under the table, you will react differently depending on whether or not you take my gesture as communicative. If you believe that I kicked your leg by accident, you will expect me to apologize. If you interpret the same behavior as communicative, you will spontaneously try to understand what I want you to understand: maybe I want to remind you that you have to say something at this point in the dinner, maybe I want to help you realize that you are about to commit some blunder. If I find a drawing on the table when I come back home, I look at it differently if I believe that my roommate did it to remember how something looked than if I believe she did it and left it on the table to tell me something. During experiences of art, as in everyday social interactions, the detection of a communicative intention can activate mechanisms specialized in the understanding of communicative acts. More precisely, the detection of a communicative intention might determine whether the mechanisms that are recruited to process a given property are those for artifact cognition or for communication.

Cinema, and notably Hollywood cinema, has developed various tools to make the communicative intentions of the movie director manifest. For instance, at the beginning of Hitchcock's Psycho we see Marion leaving her office with a great amount of company money that she is to deposit at the bank. After a cut, we find Marion in her room. Then the camera moves toward the money on the bed and zooms in on it. Then the music starts and the camera moves slowly toward a suitcase that Marion is filling. Hitchcock's communicative intention is very manifest. It is almost as if he was kicking our leg and ostensively pointing at the money and the suitcase. The content of what he wants us to understand comes also very easily to mind: Marion is stealing the money.

The detection of a communicative intention activates a general expectation of relevance. That is, if I recognize that someone ostensively addresses me, I expect this person to transmit some information that she believes to be optimally relevant for me (Sperber and Wilson, 1896). The concept of relevance is used here in the technical sense of a ratio between the cognitive effects produced by some information and the effort needed to process it. So, when I 
recognize that someone is ostensively addressing me, I expect that she believes that what she wants me to understand is worth processing-i.e., that it will allow me to derive enough cognitive effects to justify the effort of understanding her.

This general expectation of relevance guides the process of understanding and allows the receiver of a communicative act to guess what the producer wants him to understand. In the above examples, the receiver's expectation of relevance is satisfied by one single and strongly implied meaning. When I kick your leg to help you realize that you are about to commit a blunder, the strongly implied meaning 'you'd better shut up' is sufficiently relevant to satisfy the expectation of relevance activated by my behavior. In the same way, the meaning 'Marion is stealing the money' is relevant enough to satisfy the expectation of relevance.

In movies as in everyday communication, the expectation of relevance is frequently satisfied not by one strongly implied meaning but by the accumulation of many weakly implied meanings. Imagine that I am sitting in front of you in a train and that I kick your leg before looking at the landscape by the window with a smile. You spontaneously understand that I want to communicate something about the landscape and you look at it. The landscape is nice, but not nice enough for the meaning 'look how nice it is' to satisfy your expectation of relevance on its own. So you spontaneously look for other weakly implied meanings: I want to express my happiness to go on holidays, something in the landscape reminds me of a conversation we just had, etc. Maybe the connection between the landscape and our recent conversation is not fully clear even for me. By pointing it to you I want to express an impression that I could not necessarily verbalize. Pointing out the landscape with a smile allows me to express this impression without the need to verbalize it. Giving you a cue to my impression is enough to allow you to recover it by guessing what could have been my motivation to produce this communicative act at this precise moment. The process of understanding stops when you have found enough weakly implied meanings of this kind for your expectation of relevance to be satisfied.

In the middle of Psycho, the camera again shows us the money on Marion's night table in a very ostensible way. But this time the implied meaning is much less clear. We already know that the money is there, so the meaning cannot be merely to inform us of its presence. Moreover, Marion has just been murdered for reasons quite independent of the money. However, since we trust Hitchcock's intention to be relevant, our processes of understanding automatically look for various weakly implied meanings to satisfy our expectation. There might be a kind of moral content, Hitchcock telling us that Marion has been punished for stealing the money. Maybe there is also a kind of joke about the fact that many spectators 
believed that the question of whether Marion would succeed in stealing the money was the core of the whole movie. Maybe Hitchcock is asking us to memorize where the money is because something relevant will happen to it soon (another expectation that Hitchcock will violate). Our mechanisms of understanding go through weakly implied meanings of this sort until their accumulation satisfies our expectation of relevance.

Malick's Thin Red Line is paradigmatic of the use of weakly implied meanings. Nature (for instance the alligator at the beginning of the movie) is filmed like the money in Psycho. Malick seems to point to us scenes of nature so that we understand something. But when we look at these images, no clear meaning comes to mind. Many spectators do not even see these images of nature as communicative: they only see them as having the function of showing the setting in which the action takes place, so that the overall experience elicited is of a bad war movie. For the spectator who sees the images of nature as communicative and who trusts Malick's capacity to be relevant, many weakly implied meanings can come to mind. Malick might tell us that nature is blissfully indifferent to human affairs. Maybe he is asking whether human wars are part of nature or if there is a line separating human war and nature. Maybe he is asking whether the eye of god lies behind nature and whether it is indifferent, powerless or ironic (see Davies, 2009, for various attempts to put words on to some of the weakly implied meanings that can be elicited by Malick's images of nature).

The capacity of a communicative act to embody weakly implied meanings allows the artist to express non-propositional mental states such as intuitions and emotions, since the process of understanding a communicative act with no strongly implied meaning rests on the recovery of the motivations, including non-declarative ones, that have led to this communicative act. Some artworks - paradigmatically, conceptual art such as Duchamp's Fountain - might work as a whole as a communicative act that embodies many weakly and in part non-declarative meanings. The effect of attribution of meaning through psychological processes linked to communication on perception per se is an open question.

This section argued that artworks have communicative properties and that they acquire their meaning for the receiver in the same way as any other communicative act: through a reconstruction of their producer's intentions. The next section considers the possibility that artworks trigger the mechanisms that draw on one's own procedural knowledge for the perception of the actions of others.

\subsection{The perception of others' actions}


A vast amount of evidence shows that observers' procedural knowledge determines how they perceive the actions of others. That is, observers' knowledge on how to perform a given class of actions determines how they perceive actions of the same class performed by others (Aglioti et al., 2008; Calvo-Merino et al., 2005). This claim generalizes not only to the action per se but also to its static result. More precisely, performing an activity that involves the repetition of a certain class of actions builds representations at the interface between perception and action that allow the planning of those actions by anticipating their distal perceptual outcomes (Hommel et al, 2001). These very same representations can then be used during perception of the outcome of the same actions performed by others, to perceptually organize them as the result of actions that the perceiver could have performed (Drost et al., 2005; Rieger, 2007). In the case of art perception, this class of mechanisms could act upstream from, and feed into, the mechanisms devoted to artifact cognition and communication, as an initial determinant of how the properties of the work are perceptually organized.

In fact, we all perform activities with relevant similarities to artistic practices. We use pencils and related tools to write and produce at least basic drawings, we tell stories, take pictures, and many of us have at least some amateur artistic hobby. Thus, the properties of artworks frequently bear the traces in their final appearance of actions that we could have performed ourselves. Depending on perceivers' procedural knowledge of these kinds of activities, these properties can be perceived as the result of intentional actions that the perceiver could have produced. For instance, the lines of a drawing might be perceptually organized as the result of actions that the observer might have performed (Pignocchi, 2010; see Taylor et al., 2012, for an experimental exploration of this hypothesis adapted to brushstrokes). If this hypothesis is correct, the perceptual organization of the lines of a drawing already includes an implicit attribution of intentions - in this case, what philosophers call 'intentions in action' (Pacherie, 2000; Searle, 1983). This mode of perception of the lines of a drawing can be a first step toward the explicit attribution of more complex intentions. For instance, the perception of the lines in the sketches of Delacroix can provide information about the speed of the gesture and the fluidity of the sequences of different gestures (for instance, in Foule de marocains, cour et maison, porte, notes manuscrites). In addition to an impression of dexterity, the intentions in action that we see behind the lines are coherent with what we know about the eagerness of Delacroix to keep traces of what he was seeing when he was travelling in Morocco. This coherence gives an overall impression of a sincere intentional process. In the same way, in looking at drawings by Schiele, the perception of the regularity 
of speed and of the high pressure of the hand, the abrupt way in which the hand seems to have landed on the sheet and left it, are coherent with the representational content of the drawing and with the kind of nervousness it seems to express (see for instance Bildnis Arthur Roessler or Liegender weiblicher Akt mit angezogenen Beinen).

Exactly what features are encoded by the representations at the interface between perception and action is still unclear. However, it has been claimed that repeating a given class of actions makes it possible to encode more and more complex features of those actions. On one hand, this makes it possible to anticipate more and more complex features of the perceptual outcome of these actions when planning them. On the other hand, it allows one to perceive more and more complex features of the same type of actions when they are performed by others (Pignocchi, 2010). Observers without special experience in drawing may be able to perceive simple features, such as the direction of movement, the speed of the gesture, or the pressure of the hand, as the result of intentions in actions that they could have produced. Instead, for an experimented draftsman, this mode of perception relates to more complex features such as sequences of gestures, recognitional or even aesthetic properties.

Depending on the kind of activities that a given subject practices, this mode of perception, wherein the properties of an artwork are directly perceived as the result of intentions that the subject could have formed, can apply to various kinds of properties. Some structural properties of the stories in novels or movies may count among them. In fact, we all tell stories, if only in the form of anecdotes to our friends. In doing so, we generally aim to produce some effects on our audience - surprise, for instance. Thus the properties of novels or movies that are intended to produce the same kinds of effect can be directly perceived as the result of intentions that we could have formed.

\section{History, intentions and perception}

I have distinguished three families of mechanisms of intention attribution-one involved in the cognition dealing with artifacts, one devoted to communication, and one using one's own procedural knowledge to perceive the actions of others. This distinction provides support for the main claim of the intentional model: artworks trigger rich attributions of intentions.

This claim could be tested empirically by investigating the correlation between how participants evaluate an artwork and the intentions that they attribute to its author. However, using verbal evaluations as data-which is the main methodology used in studies on art within experimental psychology—raises numerous problems. Notably, it does not allow the precisely identification of what determines the responses of the participants (Reber, 2008). As 
we shall see in this section, there are preliminary reasons to believe that intention attribution influences perception per se, and thus that the intentional model can be tested without relying on the dubious methodology of using verbal evaluations as data.

Futó and collaborators (2010) have shown that ten-month-old infants who see an agent using an artifact for two different purposes have the illusion of having seen two different artifacts. This result suggests that the attribution of function might determine the perception of a given artifact. Thus, two viewers who implicitly or explicitly attribute different intentions to an artist might really see the properties of the work differently. This would be coherent with our intuitions: having read Baxandall's analysis of $A$ Woman Drinking Tea, we really have the impression that our perception of the painting has changed.

This question can be explored empirically by controlling participants' contextual knowledge about a given artwork. Different participants can be shown the same artwork while being provided with different pieces of knowledge about the artwork's context of production. Each of these pieces of knowledge may invite the attribution of a different intended function for the artwork's properties. A recognition task would test whether the participants have memorized the perceptual appearance of the artwork differently.

A subsequent question would be to check whether the effect is only attentional - the attribution of a given function attracts attention to the properties of the work that seem relevant to its fulfillment-or whether the attribution of function determines how the perceptual information is processed. This question could be addressed by contrasting the effect of contextual information that only attracts attention to some properties of the work with contextual information that invites the derivation of new inferences about the intended function of those properties. Again, intuition seems to favor the hypothesis that the attribution of function does not influence perception only through the orientation of attention but also determines the processing of perceptual information. Consider again the teapot of $A$ Woman Drinking Tea. Notice that it is strangely plain. It seems shiny, but the scene around it is not much reflected in it. Noticing this attracts attention to this property of the teapot, but this does not seem to entail the kind of deep changes in our experience that Baxandall's functional analysis does. Now, consider the possibility that what is missing on the teapot is not reflection in general, but the reflection of the woman, and that the intended function of this absence is to reinforce the impression that she is disappearing. Now that a clear connection with Chardin's intention is made, the appearance of the teapot really seems to change. Now the feeling of the teapot's presence seems to be reinforced: it looks more material than the woman, like an unpleasant witness of her disappearance. 
The same experimental paradigm-contrasting the effect of variable contextual information on a recognition task-would work for properties of artworks that are perceived as communicative acts. In this case, the impact of contextual knowledge might be particularly determinant. According to relevance theory, each communicative act rests on a guess on the producer's part about the knowledge that she shares with the receiver (Sperber \& Wilson, 1986). The producer can never be sure that the receiver has the relevant background knowledge that will enable her to understand what the producer wants her to understand. Depending on the content of the communicative act, its context, and what the producer knows about the receiver, the guess can be more or less audacious. In the case of artworks, the guess is frequently particularly audacious because, unlike in everyday communication, the artist does not address a single person whose background knowledge she can approximate. Thus, the meaning that each spectator attributes to a property of an artwork (especially when it embodies many weakly implied meanings) is likely to be extremely variable depending on her background knowledge.

In the case of the mechanisms that use one's own procedural knowledge in perception of the results of others' actions, the main source of variability comes from the spectator's experience with the relevant artistic practices (another parameter that can be controlled experimentally: Pignocchi, 2010). However, some experiments suggest that declarative contextual knowledge about intentions has a top-down influence on the perceptual segmentation of events (Zack, 2004). Thus, while it may be that only practice can create the representations used by this family of psychological mechanisms, contextual knowledge might influence which of these representations are used to perceive a given set of properties.

The intentional model sketched in this paper distinguishes three families of mechanisms that are involved in the attribution of intentions during the experience of an artwork. The functioning of each of these mechanisms is influenced in a specific way by personal background knowledge. As suggested in this section, there are preliminary reasons to believe that the functioning of these mechanisms can influence the perception of the properties of artworks - either directly or through top-down processes. If this hypothesis is correct, the processes of intention attribution identified by the intentional model constitute an intermediary step between contextual knowledge and perception. Contextual knowledge feeds the mechanisms of intention attributions which (either directly or through top-down influences) control which properties of the artwork are attended to, how they are perceptually segmented and organized, and which inferences they trigger. 
How pervasively intention attribution influences perception is an open empirical question. If it seems that intention attribution deeply influences the perception of the properties of artworks, then the intentional model would need to be reformulated in stronger terms, according to which all aspects of our experience of artworks contain a reference-at least implicit and unconscious - to the intentions of the artist.

Whether in its soft version (artworks trigger rich attributions of intentions) or its strong version (all the aspects of our experience of artworks involve reference to the intentions of the artist), the intentional model addresses the challenge issued by Bullot and Reber (in press). It shows that cognitive approaches to art can explain the role of background knowledge in the personal experience of an artwork. Moreover, unlike most cognitive approaches to art, it explains the simple observations made in the first section: the evaluation of an artwork depends on what we know about its context of production, and the evaluation of a property of an artwork depends on its role in the artwork and on the background knowledge of the observer. In fact, according to the intentional model, evaluation, be it of the whole work or of one of its properties, frequently (soft version) or always (strong version) depends on the intentions that we see behind this work or this property. More precisely, the evaluative component of our experience of an artwork can relate to the content of the attributed intention per se, how this intention seems to be realized in the work, or both (see Kaufman, 2002, for a related account of evaluation). Consider again the case of an apparent brushstroke in different contexts and seen by different observers. In a photorealistic painting, since the overall intention of the artist seems to be to cancel the traces of her actions, an apparent brushstroke is seen as a bad realization of this intention. Instead, in an impressionistic painting, the same brushstroke can be seen as the correct realization of the intention to capture an impression using a single gesture. An observer at the end of the $19^{\text {th }}$ century could see the same brushstroke in the same impressionistic painting either as the poor realization of an intention to create a traditional illusion of reality (bad realization of a valuable intention) or as the correct realization of the intention to quickly produce a careless painting (correct realization of a negatively evaluated intention). Baxandall's analysis of A Woman Drinking Tea changes both the content of the intentions we see behind the face and the teapot and how we see those intentions realized in the artwork. Imagine that at first we see them as a bad realization of the quite banal intention to produce an illusion of reality. Reading Baxandall, we progressively see the skillful realization of the subtle intentions of destabilizing perception and embodying a deep feeling. 
The take-home message of this article is that the intention attribution that determines part or all our experience of an artwork and of its properties can be implicit and unconscious. Thus, we frequently do not notice their influence. We have the impression of liking or disliking the work or its properties per se. We say that we "like" this artwork, without noticing that what we actually like is the content of the intentions that we see behind it (we find them sincere, sophisticated, original, coherent, audacious) and their skilful realization in the work.

\section{Acknowledgments}

I would like to thank Nicolas Bullot for helpful comments. Earlier versions of this paper have been presented at the Italian Academy colloquium and at Barbara Tversky's practicum, both at the Columbia University of New York.

\section{References}

Aglioti, S. M., Cesari, P., Romani, M., \& Urgesi, C. (2008). Action anticipation and motor resonance in elite basketball players. Nature Neuroscience, 11, 1109-1116.

Baxandall, M. (1985). Patterns of intention: on the historical explanation of pictures. New Haven : Yale University Press.

Beardsley, M. C. (1958). Aesthetics: Problems in the Philosophy of Criticism. New York: Harcourt Brace \& World.

Boyer, P. \& Barrett, C. (2004). Evolved Intuitive Ontology: Integrating Neural, Behavioral and Developmental Aspects of Domain-Specificity. In D. Buss (ed.), Handbook of evolutionary psychology. Cambridge, MA, MIT Press.

Bullot, N. \& Reber, R. (in press). The Artful Mind Meets Art History: Toward a PsychoHistorical Framework for the Science of Art Appreciation. Behavioral and Brain Science.

Butterfill, S. \& Apperly, I. (submitted). How to construct a minimal theory of mind.

Carroll, N. (2011). Art Interpretation. The 2010 Richard Wollheim Memorial Lecture. The British Journal of Aesthetics, 51(2), 117-135.

Carroll, N. (1999). Philosophy of art: a contemporary introduction. London: Routledge.

Calvo-Merino, B., Glaser, D. E., Grezes, J., Passingham, R. E., \& Haggard, P. (2005). Action observation and acquired motor skills: An FMRI study with expert dancers. Cerebral Cortex, 15(8), 1243-1249. 
Csibra, G. and Gergely, G. (2009). Natural pedagogy. Trends in Cognitive Sciences, 13, 14853.

Csibra, G. (2010). Recognizing communicative intentions in infancy. Mind \& Language, 25, $141-168$

Danto, A. C. (1981). The transfiguration of the commonplace: a philosophy of art. Cambridge, Mass: Harvard University Press.

Davies, S. (1991). Definitions of art. Ithaca ; London: Cornell University Press.

Davies, D, (2009). The Thin Red Line. New York: Routledge.

Drost, U. C., Rieger, M., Brass, M., Gunter, T. C., \& Prinz, W. (2005). When hearing turns into playing: Movement induction by auditory stimuli in pianists. The Quarterly Journal of Experimental Psychology Section A, 58(8), 1376-1389.

Frith, C. D., \& Frith, U. (2008). Implicit and explicit processes in social cognition. Neuron, $60,503-510$

Futó, J., Téglás, E., Csibra, G., \& Gergely, G. (2010). Communicative function demonstration induces kind-based artifact representation in preverbal infants. Cognition 117, 1-8.

Gadamer, H., G. (1975) Truth and Method. (translation ed. Garrett Barden and John Cumming. New York).

Genette, G. (1997). L'œuvre de l'art. La Relation esthétique, Paris, Seuil.

Hommel, B., Musseler, J., Aschersleben, G., \& Prinz, W. (2001). The Theory of Event Coding (TEC): a framework for perception and action planning. Behavioral and Brain Science, 24(5), 849-878; discussion 878-937.

Hyman, J. (2010). Art and Neuroscience. In Roman Frigg and Matthew Hunter (ed.), Beyond Mimesis and Convention: Representation in Art and Science. Boston Studies in the Philosophy of Science, 262, 245-261.

Iseminger, G. (1992). Intention and Interpretation, Philadelphia, Temple.

Kaufman, D. A. (2002). Normative Criticism and the Objective Value of Artworks. Journal of Aesthetics and Art Criticism, 60(2), 151-166.

Király, I., Csibra, G., \& Gergely, G. (2004). The role of communicative-referential cues in observational learning during the second year. Poster presented at the 14th Biennial International Conference on Infant Studies, May 2004, Chicago, IL, USA

Kovacs, A. M., Teglas, E., \& Endress, A. D. (2010). The social sense: Susceptibility to others' beliefs in human infants and adults. Science, 330, 1830-1834. 
Levinson, J. (2007). Artworks as artifacts. In E. Margolis \& S. Laurence (eds), Creations of the Mind: Theories of Artifacts and Their Representation (pp. 74-82). Oxford: Oxford University Press.

Levinson, J. (1989). Refining art historically. Journal of Aesthetics and Art Criticism, 47, 21 33.

Levinson, J. (1979). Defining art Historically. The British Journal of Aesthetics 19(3), 232250.

Pacherie, E. (2000). The Content of Intentions. Mind \& Language, 15(4), 400-432.

Pacherie, E. (2008). The phenomenology of action: A conceptual framework. Cognition, 107(1), 179-217.

Parsons, G., \& Carlson, A. (2008). Functional Beauty. Oxford: Clarendon Press.

Pignocchi, A. (in press). The intuitive concept of art. Philosophical Psychology.

Pignocchi, A. (2012). L'ouvre d'art et ses intentions. Paris: Odile Jacob.

Pignocchi, A. (2010). How the intentions of the draftsman shape perception of a drawing. Consciousness and Cognition, 19(4), p. 887-898.

Preissler, M. \& Bloom, P. (2008). Two-year-olds use artist intention to understand drawings. Cognition 106, 512-518.

Ramachandran, V. S., \& Hirstein, W. (1999). The science of art: a neurological theory of aesthetic experience. Journal of Consciousness Studies, 6, 15-51.

Reber, R. (2008). Art in its experience: Can empirical psychology help assess artistic value? Leonardo, 41(4), 367-372.

Reber, R., Schwarz, N., \& Winkielman, P. (2004). Processing fluency and aesthetic pleasure: Is beauty in the perceiver's processing experience? Personality and Social Psychology Review, 8(4), 364-382.

Ricoeur, P. (1976). Interpretation Theory: Discourse and the Surplus of Meaning. Fort Worth, Texas.

Rieger, M. (2007). Letters as visual action-effects in skilled typing. Acta psychologica, 126, 138-153.

Searle, J. R. (1983). Intentionality, an essay in the philosophy of mind. Cambridge [Cambridgeshire] ; New York: Cambridge University Press.

Shusterman, R. (1999). Somaesthetics: a disciplinary proposal. The Journal of Aesthetics and Art Criticism, 53(3), 299-314.

Sperber, D., \& Wilson, D. (2002). Pragmatics, modularity and mindreading. Mind \& Language, 17, 3-23. 
Sperber, D. (2000). Metarepresentations in an evolutionary perspective. In D. Sperber (ed.) Metarepresentations: An Interdisciplinary Perspective. New York: Oxford University Press.

Sperber, D., \& Wilson, D. (1986). Relevance: communication and cognition. Oxford: Basil Blackwell.

Stecker, R. (1997). Artworks: Definition, Meaning, Value. (University Park, PA: Pennstate).

Taylor, J. T., Witt, J. K., \& Grimaldi, P. J. (2012). Uncovering the connection between artist and audience: Viewing painted brushstrokes evokes corresponding action representations in the observer. Cognition, 125 ( 1), 26-36.

Topal, J., Gergely, G., Miklosi, A., Erdohegyi, A., \& Csibra, G. (2008). Infant perseverative errors are induced by pragmatic misinterpretation. Science, 321, 1831-1834.

Walton, K. L. (1970). Categories of Art. The philosophical review, 70, 334-367.

Wimsatt, W. K., \& Beardsley, M. (1954). The Intentional Fallacy. In The Verbal Icon. Lexington, University of Kentucky Press. 3-18.

Wollheim, R. (1987). Painting as an Art. London: Thames and Hudson.

Zacks, J. M. (2004). Using movement and intentions to understand simple events. Cognitive Science, 28, 979-1008. 